\title{
PENGENALAN KAJIAN ERGONOMIS TERHADAP DESAIN PRODUK UNTUK MENGEMBANGKAN KOMPETENSI BELAJAR SIWA SMK MUHAMMADIYAH I TEMON KULON PROGO
}

\author{
Eko Poerwanto \\ Program Studi Teknik Industri \\ Sekolah Tinggi Teknologi Adisutjipto Yogyakarta \\ Komplek Lanud. Adisutjipto Blok-R, Yogyakarta \\ ekoevtas@gmail.com
}

\begin{abstract}
Industry 4.0 requires creative and innovative human resources so that the products design competency of ergonomic is an important requirement for the demands of customized products. Muhammadiyah I Vocational School Temon, Kulon Progo district is a vocational school that is very close to the new International Airport for Yogyakarta, so it is a very strategic activity to provide an introduction to the Aviation Industry and Ergonomics in Product Design. This is important to provide provision for students of vocational school to be able to know the requirements and standards of service products / goods so that they can be accepted in the Aviation Industry. The results of observations in the field show that most students' understanding of HR standards for the Aviation Industry is still very lacking and understanding ergonomics in product design is still very lacking.
\end{abstract}

Keywords: produck design; ergonomic;

\begin{abstract}
Abstrak
Era Industri 4.0 membutuhkan sumber daya manusia yang kreatif dan inovatif sehingga kompetensi perancangan produk yang ergonomi menjadi kebutuhan yang cukup penting untuk tuntutan produk yang customize. SMK Muhammadiyah I Temon, kabupaten Kulon Progo merupakan sekolah kejuruan yang letaknya sangat dekat dengan Bandara Internasional baru untuk Yogyakarta, sehingga merupakan kegiatan yang sangat strategis untuk memberikan pengenalan tentang Industri Penerbangan dan Ergonomi pada Perancangan Produk. Hal ini penting dilakukan untuk memberikan bekal kepada siswasiswi lulusan SMK untuk dapat mengetahui persyaratan dan standar produk jasa/barang sehingga dapat di terima di Industri Penerbangan. Hasil pengamatan di lapangan menunjukkan bahwa sebagian besar pemahaman siswa tentang standar SDM untuk Industri Penerbangan masih sangat kurang dan pemahaman ergonomi dalam perancangan produk juga masih sangat kurang.
\end{abstract}

Kata kunci : ergonomi, desain produk 


\section{Latar Belakang Masalah}

Era globalisasi dengan segala implikasinya menjadi salah satu pemicu cepatnya perubahan yang terjadi pada berbagai aspek kehidupan masyarakat dan bila tidak ada upaya sungguh-sungguh untuk mengantisipasinya maka hal tersebut akan menjadi masalah yang sangat serius. Dalam hal dunia pendidikan mempunyai tanggung jawab yang besar, terutama dalam menyiapkan sumber daya manusia yang tangguh sehingga mampu hidup selaras di dalam perubahan itu sendiri. Pendidikan merupakan investasi jangka panjang yang hasilnya tidak dapat dilihat dan dirasakan secara instan, sehingga sekolah sebagai ujung tombak di lapangan harus memiliki arah pengembangan jangka panjang dengan tahapan pencapaiannya yang jelas dan tetap mengakomodir permasalahan faktual kekinian yang ada di masyarakat. Kajian ergonomi dalam desain produk merupakan hal yang sangat penting dalam mengantisipasi perubahan yang terus menerus menuju produk yang customize.

Customization merupakan kegiatan bisnis yang dijalankan oleh suatu perusahaan dengan menciptakan dan memberikan produk/jasa kepada konsumen yang sesuai dengan kebutuhan serta keinginan konsumennya. Perusahaan harus mampu melihat serta mengetahui dengan cepat apa yang dibutuhkan atau yang diinginkan oleh konsumennya. Pendekatan mass customization memberikan peluang untuk sedikit memanjakan keinginan konsumen. Dengan menerapkan customer care, perusahaan mulai meninggalkan pendekatan mass marketing melangkah pada mass customization. Maka dari itu di dalam kegiatan customization bisa menerapkan konsep customer care. Konsep ini diikuti perubahan paradigma pemasaran, dari hubungan bersifat transnasional menjadi hubungan yang dilandasi pemikiran jangka panjang (dan dengan sendirinya melakukan pembelian berulang), perusahaan perlu memahami pelanggan dan peduli pada mereka.

Ergonomi merupakan salah satu dari persyaratan untuk mencapai desain yang qualified, certified dan customer need. Dan seberapa jauh sebuah produk telah memenuhi aspek teknis fungsional, kualitas estetis dan ekonomis, maka dalam hal ini diperlukan pengujian yang menggunakan tolok ukur tertentu. Ergonomi diperlukan untuk evaluasi produk. Selain fungsional, desain juga harus mampu memberikan keselamatan, kesehatan, keamanan dan Kenyamanan bagi manusia pada saat memakai dan mengoperasionalkan hasil produk desain

Industri Penerbangan tidak mentolerir adanya Human Error. Sehingga sebuah rancangan produk harus memenuhi aspek teknis dan fungsional maupun aspek estetika dan ke-ergonomi-an pada saat di buat, maka dalam hal ini diperlukan berbagai macam evaluasi dan pengujian dengan menggunakan tolok ukur tertentu. Evaluasi ergonomis dalam hal ini merupakan salah satu langkah pengujian agar sebuah rancangan produk pada saat dioperasikan tidak saja mampu memberikan fungsi-fungsi yang telah direncanakan, akan tetapi juga mampu memberikan keselamatan, kesehatan dan juga kenyamanan pada saat dioperasikan. Akhirnya, rancangan produk yang ergonomis itu jelas akan mampu pula meningkatkan nilai komersial dan daya saing produk. Kegiatan pengabdian kepada masyarakat ini telah dilaksanakan di SMK Muhammadiyah I Temon Kulon Progo dan dapat memberikan pengenalan tentang kajian ergonomi terhadap desain produk maupun produk yang dapat diaplikasikan di Industri Penerbangan

Pembangunan Bandara Internasional baru di daerah Temon Kulon Progo sebagai pengganti bandara internasional Adisutjipto Yogyakarta merupakan sebuah momentum yang tepat bagi SMK Muhammadiyah I Temon Kulon Progo khususnya dan SMK-SMK lain di sekitar bandara baru tersebut pada umumnya, untuk mempersiapkan diri terhadap kualitas peserta didiknya agar sekiranya mampu dan dapat mengikuti perkembangan kebutuhan lapangan kerja terutama lapangan kerja yang berhubungan dengan bidang penerbangan. Namun demikian terdapat beberapa kendala yang dihadapi di antaranya : 
1. Belum mengetahui gambaran mengenai standar produk jasa/barang yang terdapat pada industri penerbangan.

2. Belum mengetahui skil-skill apa saja yang perlu dipersiapkan untuk bekerja pada industri penerbangan.

3. Pengetahuan tentang industri penerbangan yang tidak mentolerir adanya Human Error pada setiap rancangan dan operasional produknya.

Berdasarkan beberapa kendala tersebut, maka kegiatan pengabdian pada masyarakat terutama bagi siswa-siswi SMK Muhammadiyah I Temon Kulon Progo khususnya dan SMK-SMK lain di sekitar bandara baru tersebut pada umumnya, merupakan kegiatan yang sangat strategis untuk memberikan bekal pengetahuan bagi masyarakat.

\section{Metodologi Penelitian}

Metode Pelaksanaan Pengabdian pada Masyarakat ini meliputi beberapa komponen yaitu:

a. Sumber Daya Manusia (SDM)

Metode yang dipilih untuk memenuhi kebutuhan SDM dengan melakukan pemetaan kompetensi terhadap Siswa Siswi SMK Muhammadiyah I Temon dengan materi yang diberikan dalam pelatihan ini disesuaikan dengan kurikulum yang berlaku bagi SMK tersebut.

b. Keterbatasannya fasilitas teknologi yang mendukung.

Keterbatasan fasilitas komputer untuk pelajaran Teknologi Perancangan Produk, diselesaikan dengan mengadakan pelatihan dan pendampingan menggunakan komputer yang terbatas kemudian menggunakan Viewer untuk peragaan secara visual di depan kelas.

c. Proses

Setelah dilakukan pengarahan tentang standar produk dan standar SDM pada industri penerbangan, kemudian dilanjutkan dengan pelatihan cara perancangan yang mempertimbangkan kajian ergonomi, serta dilanjutkan dengan pendampingan dalam menggunakan software Catia.

d. Produk

Menghasilkan siswa siswi SMK Muhammadiyah I Temon yang mampu memahami standar produk dan standar SDM pada industri penerbangan serta mampu memahami kajian ergonomi dalam perancangan produk dan dapat menggunakan teknologi perancangan yaitu komputer, dengan software Catia.

e. Manajemen

Setelah melakukan sosialisasi, dilanjutkan dengan memberikan pendampingan kepada siswa siswi SMK Muhammadiyah I Temon untuk dilatih dalam menggunakan perangkat lunak Catia tersebut hingga menguasai dengan baik. Pihak SMK Muhammadiyah I Temon berharap ada kerja sama yang berkesinambungan untuk pengembangan kompetensi baru di industri penerbangan.

\section{Hasil dan Pembahasan}

SMK Muhammadiyah 1 Temon atau yang dikenal SMK MUTU merupakan salah satu SMK yang terletak di Kecamatan Temon Kabupaten Kulon Progo Provinsi DIY. SMK MUTU ini berdiri pada tahun 1997. Dan sampai saat ini telah memiliki 5 Jurusan atau Program Kompetensi Keahlian. 
1. Teknik Audio Video

2. Teknik Komputer dan Jaringan

3. Teknik Kendaraan Ringan

4. Multimedia

5. Teknik Sepeda Motor

Meski setiap Jurusan memiliki keunggulan masing-masing, namun SMK MUTU selalu fokus pada satu tujuan yaitu, Membina insan yang handal dalam IPTEK dan IMTAQ.

Kegiatan di industri penerbangan dapat dikelompokkan menjadi 3 kelompok yaitu : Aircraft Manufacture, Aircraft Operation dan Aircraft Maintenance. Berdasarkan ke tiga kelompok kegiatan di industri penerbangan serta kelima kompetensi keahlian inilah lulusan SMK Muhammadiyah I Temon dapat dipetakan untuk dapat mengisi SDM di industri penerbangan, sebagai berikut :

Tabel 1 Pemetaan Kompetensi Lulusan SMK untuk Industri Penerbangan

\begin{tabular}{|c|c|c|c|c|}
\hline Kompetensi Keahlian & $\begin{array}{c}\text { Aircraft } \\
\text { Manufacture }\end{array}$ & $\begin{array}{l}\text { Aircraft } \\
\text { Operation }\end{array}$ & $\begin{array}{c}\text { Aircraft } \\
\text { Maintenance }\end{array}$ & Keterangan \\
\hline Teknik Audio Video & - & bisa & bisa & \multirow{5}{*}{$\begin{array}{c}\text { Harus mengikuti } \\
\text { Pendidikan } \\
\text { tambahan } \\
\text { Khusus }\end{array}$} \\
\hline $\begin{array}{l}\text { Teknik Komputer dan } \\
\text { Jaringan }\end{array}$ & bisa & bisa & bisa & \\
\hline $\begin{array}{l}\text { Teknik Kendaraan } \\
\text { Ringan }\end{array}$ & bisa & bisa & bisa & \\
\hline Multimedia & - & bisa & bisa & \\
\hline Teknik Sepeda Motor & bisa & bisa & bisa & \\
\hline
\end{tabular}

Berdasarkan tabel 1 di atas banyak siswa-siswi SMK Muhammadiyah I Temon yang heran dan bertanya-tanya, mengapa para lulusan sekolah yang sangat berdekatan dengan bandar udara baru di DIY tersebut tidak dapat bekerja langsung di Industri Penerbangan, tetapi harus mengikuti pendidikan tambahan khusus yang disyaratkan berdasarkan regulasi di Industri Penerbangan. Bahkan guru-guru yang mendampingi kami dalam program pengabdian ini juga merasa sedih, karena kompetensi yang telah diberikan sesuai dengan kurikulum dari Diknas-pun kurang memenuhi standar yang dibutuhkan di Industri Penerbangan.

Pendidikan tambahan khusus yang dapat diberikan sehingga mereka dapat bekerja di Industri Penerbangan di antaranya :

1. Sekolah Penerbangan.

2. Pendidikan dan Pelatihan Ground Handling Services

3. Pendidikan dan Pelatihan untuk Cabin Crew.

4. Pendidikan dan Pelatihan Pengatur Lalulintas Penerbangan.

5. Pendidikan dan Pelatihan Perawatan Pesawat, dll.

Pendidikan dan pelatihan tersebut semata-mata untuk memenuhi standar kompetensi yang diwajibkan sesuai dengan regulasi penerbangan sipil, sesuai dengan ICAO (International Civil Aviation Organization). Hal inilah yang menjadikan para guru dan kepala sekolah SMK Muhammadiyah I Temon berharap program pengabdian pada masyarakat ini dapat dilanjutkan dan dikembangkan untuk dapat meningkatkan kompetensi lulusannya sehingga dapat diterima di Industri Penerbangan. Pada tahun-tahun mendatang SMK Muhammadiyah I Temon juga berharap dapat menambah program kompetensi baru di bidang Industri Penerbangan yang bersertifikasi sesuai dengan standar regulasi yang ditetapkan.

Kegiatan pelatihan kajian ergonomi untuk perancangan desain produk dapat diikuti oleh seluruh siswa-siswi SMK Muhammadiyah I Temon dengan memberikan pengarahan tentang kemungkinan produk yang dapat dibutuhkan oleh masyarakat pada umumnya, 
karena tidak semua lulusan SMK Muhammadiyah I Temon juga berminat di Industri Penerbangan. Kegiatan Perancangan Produk dengan menggunakan software Catia mempunyai banyak kelebihan, dan yang memudahkan analisisnya yaitu tentang kajian ergonomi dapat langsung disimulasikan di software ini. Beberapa contoh hasil rancangan adalah sebagai berikut :
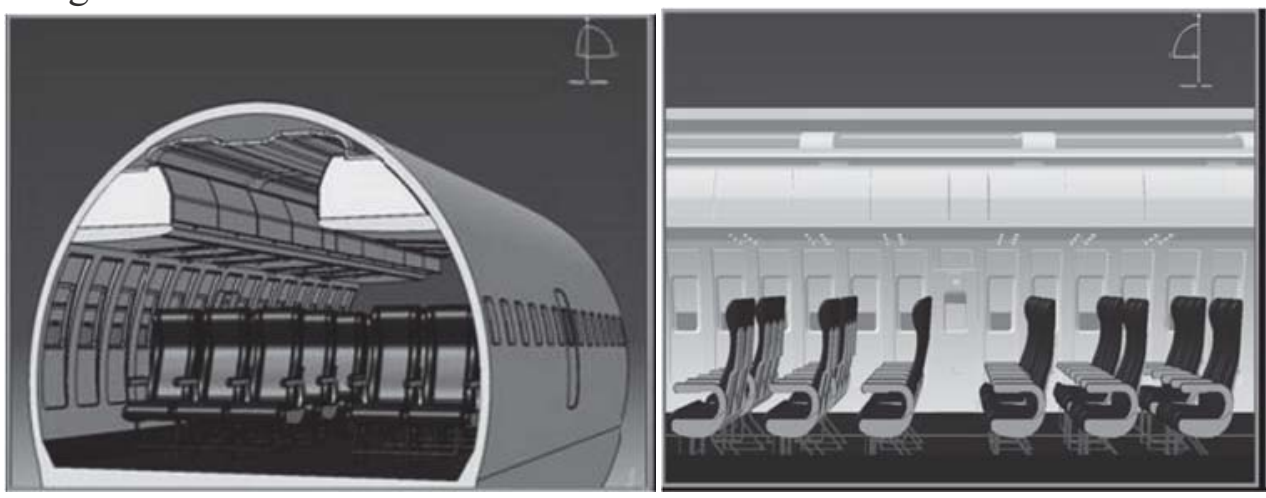

Gambar 1 Contoh Perancangan menggunakan Software Catia.

Rancangan memenuhi kriteria "baik" sejauh rancangan tersebut mampu memenuhi tolok ukur efektif, efisien, nyaman, aman, dan sehat dan Efisien. Problem utama adalah bagaimana cara pengukurannya. Esensi dasar dari evaluasi ergonomis dalam proses perancangan produk adalah sedini mungkin mencoba memikirkan kepentingan manusia agar bisa terakomodasikan dalam setiap kreativitas dan inovasi sebuah"man-made object". Pendekatan yang terfokus melalui pertimbangan faktor manusia merujuk ke konsep perancangan yang utamanya ditujukan untuk memenuhi kebutuhan dan kepuasan manusia.

Beberapa dokumentasi pada kegiatan pengabdian masyarakat di SMK Muhammadiyah 1 Temon kabupaten Kulonprogo adalah sebagai berikut :

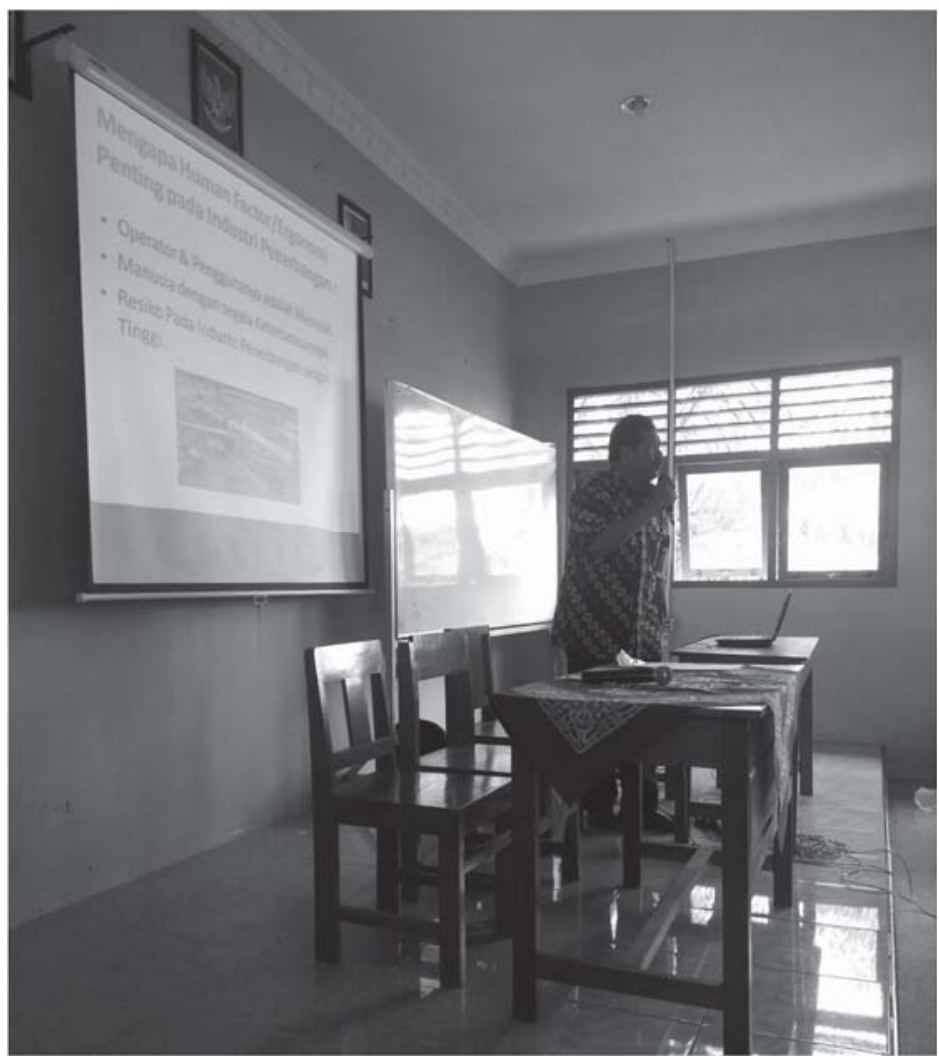

Gambar 2 Gambar Pengarahan Kajian Ergonomi 
untuk Desain Produk di SMK Muh. I Temon.

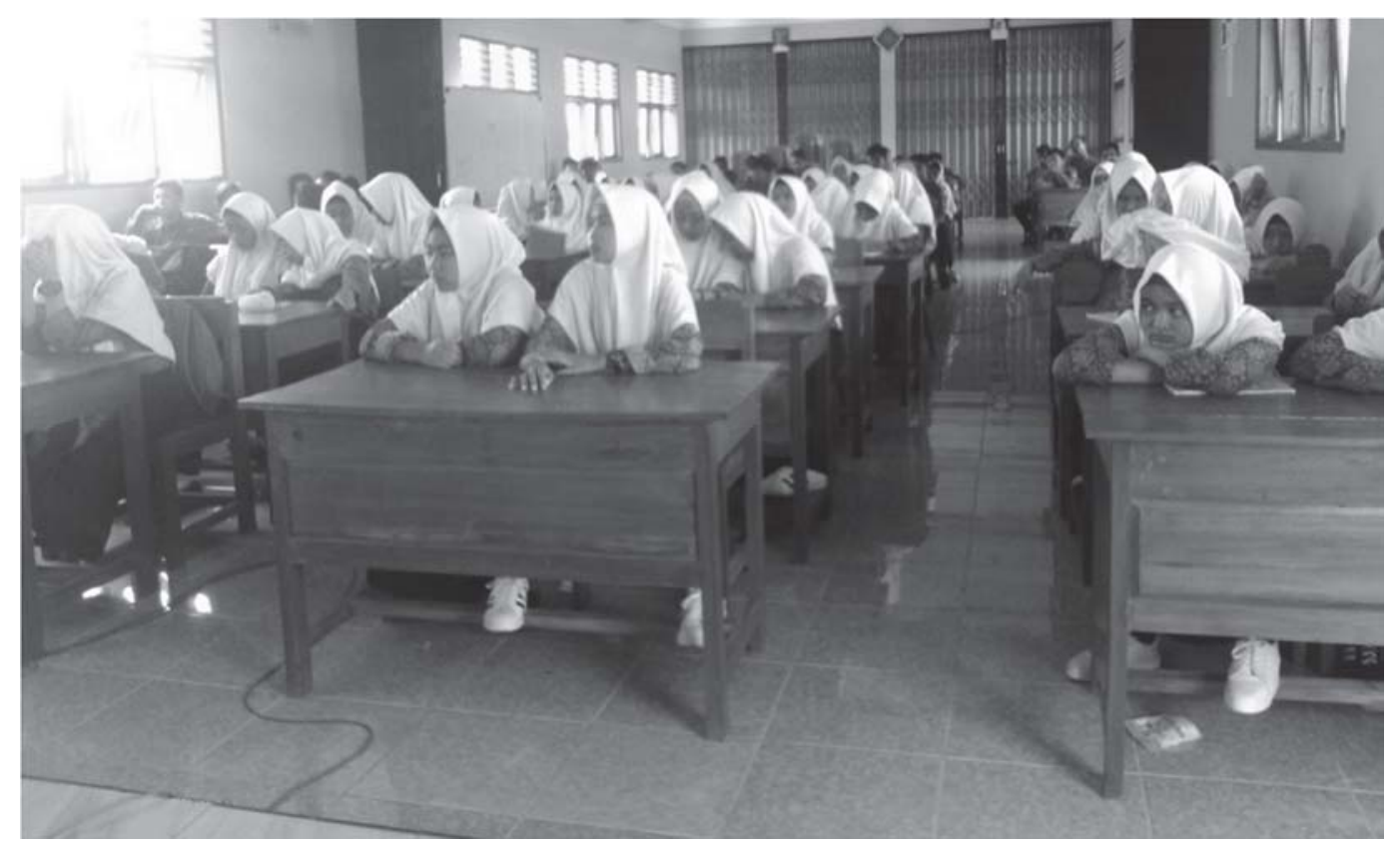

Gambar 3 Gambar Peserta Pengarahan Kajian Ergonomi untuk Desain Produk di SMK Muh. I Temon.

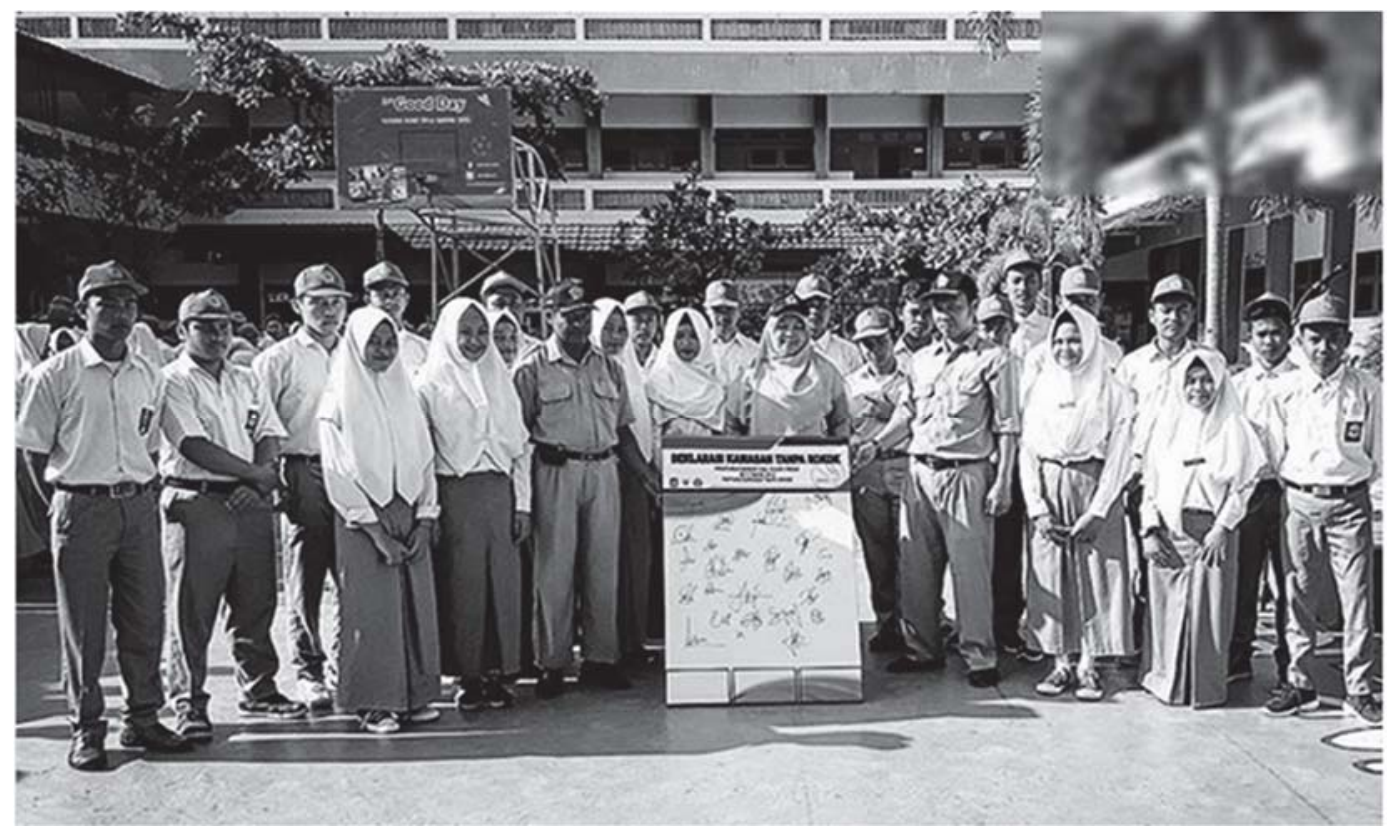

Gambar 4 Kepala Sekolah, guru dan Siswa-siswi SMK Muh. I Temon.

\section{Kesimpulan}

Berdasarkan uraian di pembahasan tersebut di atas, ada beberapa kesimpulan yang dapat dilakukan sebagai berikut :

a. Kompetensi lulusan yang dihasilkan SMK Muhammadiyah I Temon tidak dapat langsung mengisi tenaga kerja di Industri Penerbangan.

b. Perlu adanya tambahan kompetensi baru dan bersertifikasi sesuai dengan regulasi di Industri Penerbangan sehingga lulusan SMK Muhammadiyah I Temon dapat diterima di Industri Penerbangan. 
c. Kompetensi perancangan desain produk yang ergonomi dapat menjadikan nilai tambah bagi lulusan SMK Muhammadiyah I Temon untuk industri pada umumnya.

Ucapan terima kasih diucapkan kepada SMK Muhammdiyah I Temon yang telah memberikan waktu dan fasilitas untuk terlaksananya kegiatan pengabdian masyarakat ini. Besar harapan kegiatan ini dapat dikembangkan menjadi kerja sama dengan Sekolah Tinggi Teknologi Adisutjipto, sehingga dapat bersinergi bersama dalam menyiapkan SDM untuk Industri Penerbangan.

\section{Daftar Pustaka}

[1] A. Rudianto. (2017), Kajian Ergonomi Pada Visual Display Penunjuk Informasi Pelabuhan di Kawasan Kuala Enok, Jurnal BAPPEDA “Selodang Mayang”, Vol.3 No. 1, April 2017, ISSN : 2442-7845, Halaman 30-34

[2] Poerwanto, E., \& Mauidzoh, U. (2016). Analisis Kecelakaan Penerbangan Di Indonesia Untuk Peningkatan Keselamatan Penerbangan. Angkasa: Jurnal Ilmiah Bidang Teknologi, 8(2), 9-26.

[3] Poerwanto, E., \& Gunawan, G. (2015). Analisis Beban Kerja Mental Pekerja Bagian Ground $\mathrm{H}$ Andling Bandara Adisutjipto untuk Mendukung Keselamatan Penerbangan. Angkasa: Jurnal Ilmiah Bidang Teknologi, 7(2), 115-126.

[4] Panduan Pelaksanaan Penelitian dan PPM Edisi X 2016, www. simlitabmas.ristekdikti.go.id, diakses pada tanggal 18 April 2018. 